\title{
Use of Amphiphilic Composites based on Clay/Carbon Nanofibers as Fillers in UHMWPE
}

\author{
Claudilene R. Silva, ${ }^{a}$ Rochel M. Lago, ${ }^{* a}$ Helena S. Veloso ${ }^{b}$ and Patrícia S. O. Patricio ${ }^{b}$ \\ ${ }^{a}$ Departamento de Química, Universidade Federal de Minas Gerais (UFMG), \\ Av. Antônio Carlos, Pampulha, 31270-901 Belo Horizonte-MG, Brazil \\ ${ }^{b}$ Centro Federal de Educação Tecnológica (CEFET), \\ Avenida Amazonas, 5253, Nova Suiça, 30421-169 Belo Horizonte-MG, Brazil
}

\begin{abstract}
In this work, it is proposed a new strategy to improve the dispersion of inorganic fillers in polymeric matrices by producing surface carbon nanostructures. Clay/carbon nanofibers particles were prepared and used as fillers to improve the mechanical and thermal properties of ultra-high molecular weight polyethylene (UHMWPE). Thermogravimetry (TG), differential scanning calorimetry (DSC), elemental analyses, Raman, X-ray diffraction (XRD) and scanning electron microscopy (SEM) showed that chemical vapor deposition (CVD) with ethanol at different temperatures, i.e. 700,800 and $900{ }^{\circ} \mathrm{C}$ with and without Fe catalyst, can be used to produce carbon (0.5-3.6 wt.\%), mainly as nanofibers, on the clay surface. The use of these clay/carbon particles as fillers in UHMWPE at 1 and $3 \mathrm{wt} \%$ produced an increase in the yield stress from 16 to ca. $20 \mathrm{MPa}$ and Young modulus from $314 \mathrm{MPa}$ for pure UHMWPE to values near 395-408 MPa. Moreover, the presence of the carbon/clay composites led to a strong improvement of the thermal properties of the UHMWPE increasing the decomposition $\mathrm{T}_{\text {onset }}$ (degradation start temperature) from 445 up to $472{ }^{\circ} \mathrm{C}$. It was also observed by the crystallization enthalpies that the UHMWPE increased the crystallinity from 55 to $80-85 \%$ in the presence of the carbon composites. These results are discussed in terms of the strong interactions of the hydrophobic carbon nanostructures on the clay surface with the polymer hydrophobic chains.
\end{abstract}

Keywords: amphiphilic composites, carbon nanofibers, montmorillonite, ultra-high molecular weight polyethylene

\section{Introduction}

Ultra-high molecular weight polyethylene (UHMWPE) is an important polymer in different applications, such as unit conveying as chain guides, star wheels, feed screws, truck beds in mining, suction box covers in hopper bunker liners, rollers, foil blades, in medical applications, e.g. artificial knee, shoulder and hip implants, food preparation surfaces, lead acid battery separators, in cloth ballistic, fishing line, nets and recreational as snow ski soles, snow mobile boogie wheels.

Several inorganic fillers such as silica, ${ }^{2}$ talc $^{3}$ and specially clays ${ }^{4}$ have been used to improve the UHMWPE properties. However, due to the complex processing of UHMWPE the dispersion of these inorganic hydrophilic particles is very difficult. Therefore, the main inorganic filler used, the clay montmorillonite (MMT), is usually

*e-mail: rochellago@gmail.com modified in order to introduce an organophilic character to the particles. A typical modification is the introduction of a quaternary ammonium salt. Babaei et al..$^{5}$ investigated the thermal and mechanical properties of UHMWPE fiber reinforced HDPE (high density polyethylene) and nanoclay Cloisite ${ }^{\circledR} 20 \mathrm{~A}$ which showed a slightly improvement of the mechanical properties of UHMWPE with an increase in the crystallinity. Gai and $\mathrm{Li}^{6}$ studied the mechanical and rheological properties of UHMWPE/PP (polypropylene) and nanoclay blends with $1-3 \%$ organophilic montmorillonite which increased the composite tensile strength. Babiker and Muhuo ${ }^{7}$ evaluated the thermal and mechanical properties of UHMWPE upon the addition of the commercial Cloisite ${ }^{\circledR} 15 \mathrm{~A}$ and observed a general improvement of the polymer properties. Santhoskumar et al. ${ }^{8}$ studied the addition of Cloisite ${ }^{\circledR} 30 \mathrm{~B}$ at 1 and $3 \mathrm{wt} . \%$ to improve the mechanical properties of UHMWPE/EVA (ethylene vinyl acetate) blends. 
Carbon structures, especially nanoparticles such as nanotubes and graphene, are known to disperse very well in UHMWPE due to the high surface area and hydrophobic character. ${ }^{9-11}$ In this work, we combined the properties of the MMT clay with carbon nanofibers to produce a filler for UHMWPE based on nanostructured composite particles. These nanostructured particles are composed of surface grown carbon nanostructures which are highly hydrophobic and should improve the interaction with the UHMWPE and increase the particle dispersion in the polymeric matrix (Figure 1).

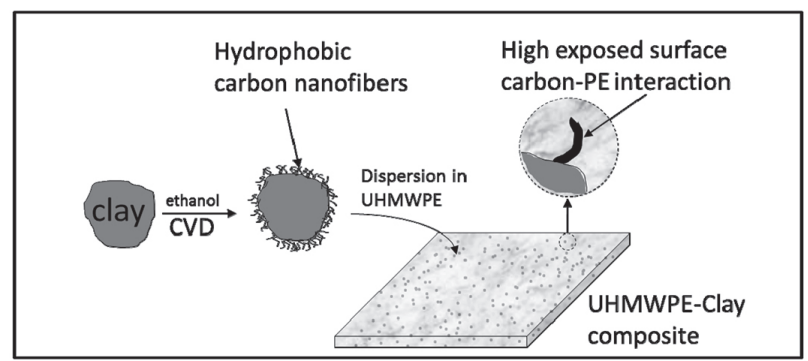

Figure 1. Schematic representation of the CVD synthesis of the carbon nanofibers/clay particles and interaction with the UHMWPE matrix.

This carbon nanostructure can be grown on the surface of inorganic materials such as clays, e.g. montmorillonite, ${ }^{12}$ vermiculite, ${ }^{13-17}$ serpentinite, ${ }^{15}$ chrysotile, ${ }^{18,19}$ mining wastes $^{20-23}$ by the chemical vapor deposition (CVD) method using different carbon sources, e.g. methane and ethanol. Hereon, the amphiphilic particles based on carbon nanofibers produced on the surface of montmorillonite using ethanol were characterized and dispersed in UHMWPE. The improvement of the mechanical and thermal properties of the polymeric composites obtained are described.

\section{Experimental}

The montmorillonite (MMT) sample (Santa Gena Mine, Argentina) was purified by the Stokes method to remove quartz and feldspar, and showed approximate chemical composition of: $\mathrm{SiO}_{2}: 54.7 \%, \mathrm{Al}_{2} \mathrm{O}_{3}: 16.5 \%, \mathrm{Fe}_{2} \mathrm{O}_{3}$ : 4.5\%, $\mathrm{MgO}: 3.1 \%, \mathrm{Na}_{2} \mathrm{O}: 3.3 \%, \mathrm{TiO}_{2}: 0.8 \%, \mathrm{CaO}: 0.3 \%$, $\mathrm{K}_{2} \mathrm{O}: 0.1 \%$ and $\mathrm{MnO}: 0.1 \%{ }^{24}$ with a simplified formula $\left[\left(\mathrm{Si}_{7.99} \mathrm{Al}_{0.01}\right)_{\mathrm{IV}}\left(\mathrm{Al}_{2.72} \mathrm{Mg}_{0.54} \mathrm{Fe}_{0.50} \mathrm{Ti}_{0.09} \mathrm{Mn}_{0.003}\right)_{\mathrm{VI}} \mathrm{O}_{20}(\mathrm{OH})_{4} \mathrm{M}_{0.90}\right]$. The measured CEC (cation exchange capacity) of the natural clay mineral is 0.89 meq g $^{-1}$ of clay mineral, where its principal cation is $\mathrm{Na}^{+}\left(0.53 \mathrm{meq} \mathrm{g}^{-1}\right.$ clay mineral). The ethanol was supplied by Labsynth and used as received.

The CVD process was performed in a quartz tube with the montmorillonite and the carbon source (ethanol) was introduced through an inert gas $\left(\mathrm{N}_{2}\right)$. The flow rate of ethanol was $0.022 \mathrm{~mL} \mathrm{~min}^{-1}$ controlled by an injection pump. Syntheses were conducted by increasing the temperature at $10{ }^{\circ} \mathrm{C}$ up to three temperatures, 700,800 and $900{ }^{\circ} \mathrm{C}$ for one hour.

The preparation of the composites with UHMWPE (obtained from Braskem, $3 \times 10^{6} \mathrm{~g} \mathrm{~mol}^{-1}$ ) was carried out by compression molding using a press Solab equipment SL11 model. UHMWPE in the form of powder was mixed with the puree montmorillonite (pretreated at $800{ }^{\circ} \mathrm{C}$ ) and the carbon/M (montmorillonite) composites in powder form. They were arranged in an open mold and subjected to a temperature at $220^{\circ} \mathrm{C}$ and pressure 8.3 bar for $40 \mathrm{~min}$. The contents of pure and modified montmorillonite used in the mixtures were 1 and $3 \mathrm{wt} . \%$.

\section{Characterization of nanoparticles}

Pure and modified montmorillonite were characterized to investigate the efficiency of deposition and morphology of structures carbon. The elemental analyses (CHN PerkinElmer 2400) were performed to determine the amount of deposited carbon. Thermogravimetric (TG) curves were obtained using a Shimadzu DTG60H-DTA model. The samples were heated from ambient temperature to $900{ }^{\circ} \mathrm{C}$, at $10{ }^{\circ} \mathrm{C} \mathrm{min}{ }^{-1}$ and air flow of $50 \mathrm{~mL} \mathrm{~min}{ }^{-1}$. Raman spectra were obtained in a Bruker Senterra mark equipped with a CCD detector. The laser length of $633 \mathrm{~nm}$ was used for excitation of the sample. The scanning electron microscopy analyses (SEM) were performed on Quanta 200 FEG FEI 2006 equipment. The samples were metalized with a thin layer of gold for morphological analysis. X-ray diffraction analyses were performed in a Shimadzu 7000 with $\mathrm{Cu} \mathrm{K} \alpha$ radiation.

\section{Characterization of nanocomposites}

The tensile test was conducted at universal testing machine, Shimadzu, model Autograph AG-X. The test samples were cut using a mold of dimensions based on ASTM D638. ${ }^{25}$ They were used at seven bodies of tensile tests for each sample. The test speed was $50 \mathrm{~mm} \mathrm{~min}^{-1}$. The thermogravimetric analysis followed the same analysis protocol described for evaluating nanoparticles samples but the finish temperature was $600{ }^{\circ} \mathrm{C}$ and the atmosphere was inert $\left(\mathrm{N}_{2}\right)$. Differential scanning calorimetry (DSC) was performed using equipment of the Shimadzu model DSC-60. The analysis was performed in order to obtain the melting temperature $\left(\mathrm{T}_{\mathrm{m}}\right)$, and degree of crystallization $(\mathrm{X})$. The amount of sample used was 8 to $12 \mathrm{mg}$. The analysis was carried out in an inert medium, with nitrogen gas with a flow rate of $50 \mathrm{~mL} \mathrm{~min}^{-1}$. The sample was heated from 20 to 
$150{ }^{\circ} \mathrm{C}$ with a heating rate of $10{ }^{\circ} \mathrm{C} \mathrm{min}^{-1}$ and an isotherm was taken after $5 \mathrm{~min}$.

\section{Results and Discussion}

\section{Characterization of the carbon-clay particles}

The carbon nanostructures were synthesized on the montmorillonite clay by a CVD process using ethanol as carbon source at the temperatures 700,800 and $900{ }^{\circ} \mathrm{C}$. The montmorillonite clay was also impregnated with a catalyst, $\mathrm{Fe}^{3+}$ at 5 wt. \%, and reacted at $800{ }^{\circ} \mathrm{C}$ with ethanol. These samples are named hereon as, e.g. $\mathrm{M}_{700}$ (montmorillonite exposed to ethanol at $700{ }^{\circ} \mathrm{C}$ ) and $\mathrm{M}_{\mathrm{Fe} 800}$ (montmorillonite impregnated with $5 \% \mathrm{Fe}$ exposed to ethanol at $800{ }^{\circ} \mathrm{C}$ ).

The carbon contents of the obtained samples were analyzed by thermogravimetric curves and carbon elemental analyses. The results are shown in Figure 2.

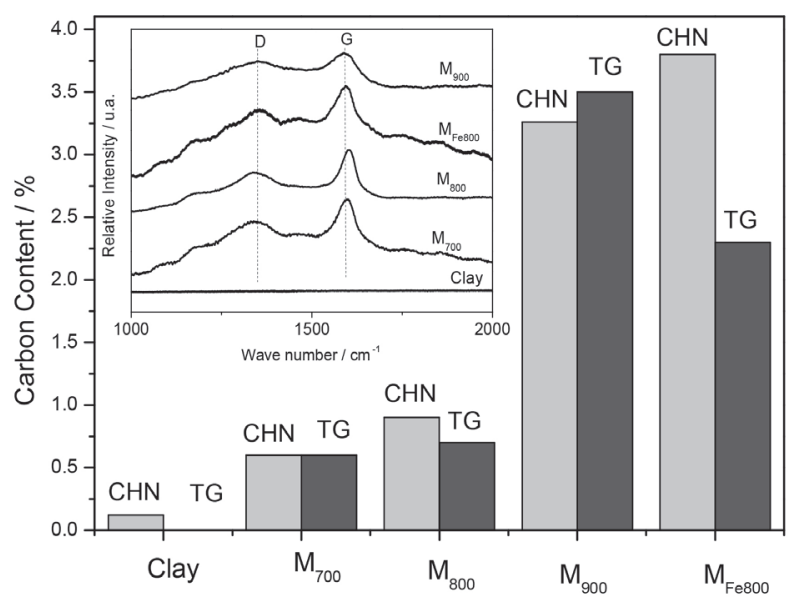

Figure 2. Carbon contents obtained by TG and CHN analyses and Raman spectra for the samples after CVD.

TG in air atmosphere of the pure clay MMT (not shown here) thermally pre-treated at $500{ }^{\circ} \mathrm{C}$ did not show any significant weight loss. The samples $\mathrm{M}_{700}$ and $\mathrm{M}_{800}$ (montmorillonite exposed to ethanol at $800{ }^{\circ} \mathrm{C}$ ) showed small exothermic weight losses, ca. $0.5-1.0 \%$, at temperatures near $400{ }^{\circ} \mathrm{C}$ likely related to the oxidation of deposited carbon. The sample $\mathrm{M}_{900}$ (montmorillonite exposed to ethanol at $900^{\circ} \mathrm{C}$ ) showed slightly higher weight loss of ca. $3 \%$ also probably related to carbon oxidation. Similar results were obtained by carbon elemental analyses (Figure 1). On the other hand, the sample containing $\mathrm{Fe}$ catalyst, i.e. $\mathrm{M}_{\mathrm{Fe} 800}$, showed the formation of carbon varying from ca. 2.4-3.6\%. This small difference between the TG and $\mathrm{CHN}$ results is likely related to the use of small amounts of sample, i.e. $2-8 \mathrm{mg}$ with the heterogeneity problems of the sample.
Raman spectra showed the typical carbon bands, i.e. the $\mathrm{G}$ band at $1600 \mathrm{~cm}^{-1}$ and the $\mathrm{D}$ band near $1340 \mathrm{~cm}^{-1}$ (Figure 2). The $\mathrm{D}$ band is related to defects in the carbon structure and the $\mathrm{G}$ band features more organized carbons, e.g. graphene/graphitic sheets. ${ }^{26}$ The $\mathrm{I}_{\mathrm{D}} / \mathrm{I}_{\mathrm{G}}$ band intensity ratio can be used to indicate relation of amorphous/ organized deposited carbon. The composites obtained at 700 and $800{ }^{\circ} \mathrm{C}$ showed similar low $\mathrm{I}_{\mathrm{D}} / \mathrm{I}_{\mathrm{G}}$ ratio of 0.43 and 0.42 , respectively, indicating a more organized type of carbon formed. On the other hand, for the samples $\mathrm{M}_{900}$ and $\mathrm{M}_{\mathrm{Fe} 800}$, which produced much more carbon, the $I_{D} / I_{G}$ ratio increased to 0.56 and 0.76 , respectively, suggesting the formation of carbon structures containing more defects.

Figure 3 shows the XRD patterns of the materials, i.e. pure clay montmorillonite, $\mathrm{M}_{700}, \mathrm{M}_{800}, \mathrm{M}_{900}$ and $\mathrm{M}_{\mathrm{Fe} 800}$.

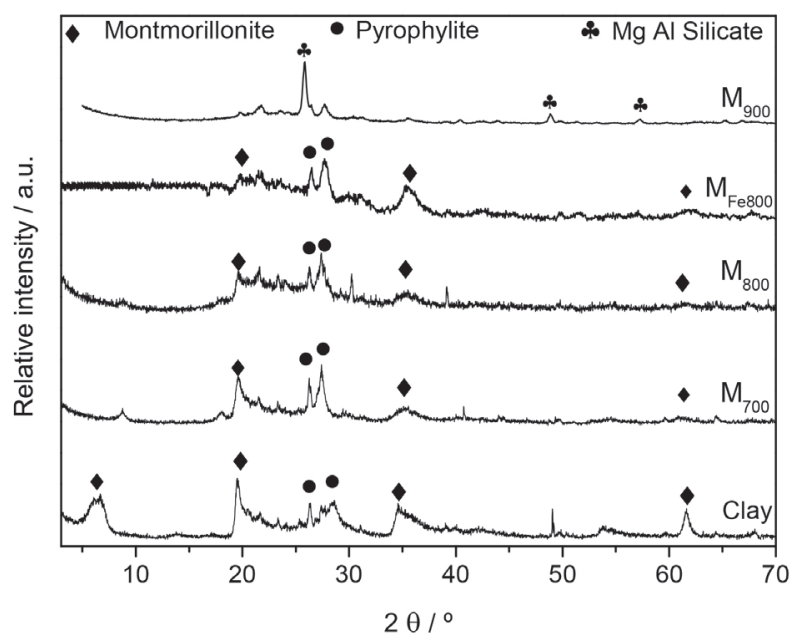

Figure 3. X-ray diffraction patterns of montmorillonite before and after CVD with ethanol at $700-900{ }^{\circ} \mathrm{C}$.

Pure montmorillonite clay showed the typical peak at $2 \theta$ ca. $8^{\circ}$ corresponding to the basal plane spacing $\mathrm{d}_{001},{ }^{27}$ associated to the lamellar structure of the MMT. After CVD at $700{ }^{\circ} \mathrm{C}$, the $\mathrm{d}_{001}$ diffraction disappeared indicating the collapse of the lamellar structure. However, some of the other peaks present in the clay XRD are still present after CVD, for example at ca. 20 and $35^{\circ}$ related to pyrophylite. It can also be observed a gradual loss of crystallinity of the samples after the treatments at $700-800{ }^{\circ} \mathrm{C}$. At $900{ }^{\circ} \mathrm{C}$ the structures present collapse to form a more crystalline magnesium aluminum silicate.

Scanning electron microscopy was used to investigate the morphology of deposited carbon structures (Figure 4). It can be observed a rough and irregular surface for the original clay. No significant difference was observed on surface morphology after CVD at $700{ }^{\circ} \mathrm{C}$ and it was not possible to clearly observe carbon structures on the surface. 


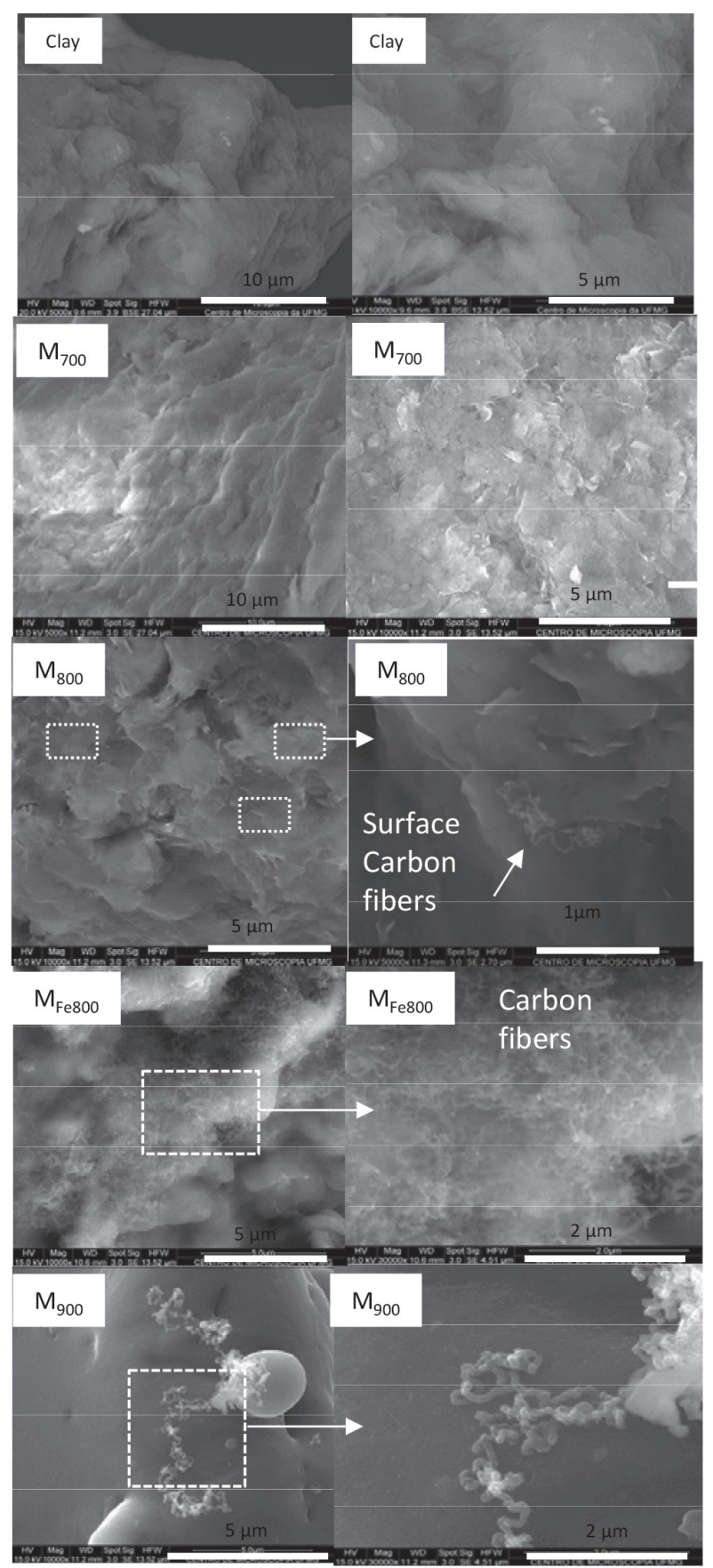

Figure 4. SEM images of montmorillonite before and after CVD with ethanol at $700-900{ }^{\circ} \mathrm{C}$.

On the other hand, at $800{ }^{\circ} \mathrm{C}$, few carbon filaments could be observed after CVD and the surface seemed more smooth suggesting a sintering process. In the presence of Fe catalyst, large amounts of entangled carbon fibers are produced indicating a clear catalytic effect on the production of carbon fibers. After treatment at $900{ }^{\circ} \mathrm{C}$ the surface became completely smooth and regular suggesting a strong sintering effect with some carbon fibers exposed on the surface.

\section{Characterization of polymeric matrix nanocomposite}

The UHMWPE composites were prepared with 1 and $3 \mathrm{wt} . \%$ of the clay/carbon particles by compression molding at $220{ }^{\circ} \mathrm{C}$ and 8.3 bar. These samples are named hereon as $1 \% \mathrm{M}_{700}$ (UHMWPE containing $1 \mathrm{wt} . \%$ of the carbon/clay composite obtained at $700{ }^{\circ} \mathrm{C}$ ). Reference materials were also prepared using UHMWPE with pure MMT clay (pretreated at $800{ }^{\circ} \mathrm{C}$ ), named hereon as $1 \% \mathrm{M}$ and $3 \% \mathrm{M}$. Initial results comparing yield stress for the materials obtained with $1 \mathrm{wt} . \%$ of the different materials are shown in Figure 5.

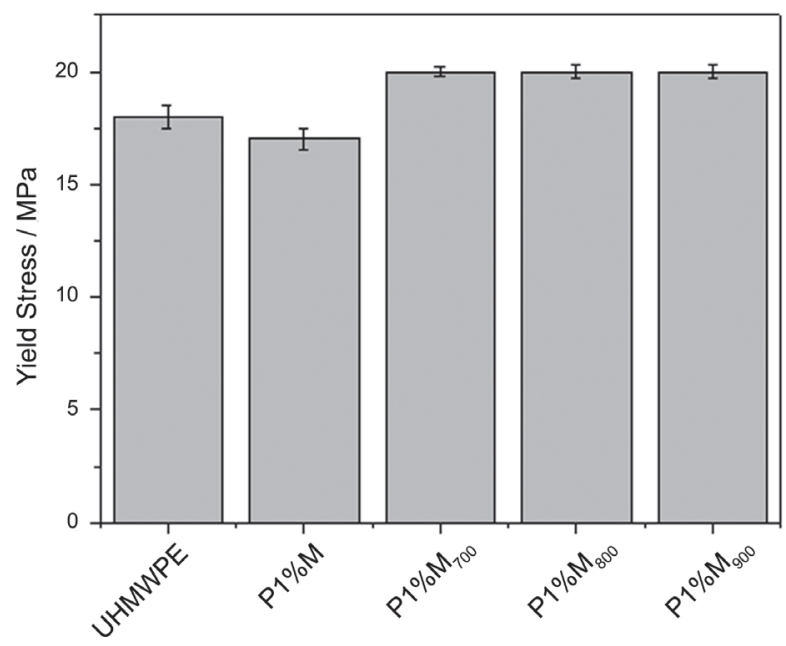

Figure 5. Yield strength values obtained from the stress-strain curves of pure UHMWPE, $1 \% \mathrm{M}, 1 \% \mathrm{M}_{700}, 1 \% \mathrm{M}_{800}$ and $1 \% \mathrm{M}_{900}$.

It can be observed that the yield stress of the pure UHMWPE of ca. 18 MPa slightly decreased when $1 \mathrm{wt} . \%$ of pure $\mathrm{M}$ was added. On the other hand, a significant increase to approximately $20 \mathrm{MPa}$ was observed upon the addition of $1 \mathrm{wt} . \%$ of the composites $\mathrm{M}_{700}, \mathrm{M}_{800}$ and $\mathrm{M}_{900}$. It is also interesting to observe that the Young's module showed similar values for pure UHMWPE $(314 \pm 57 \mathrm{MPa})$ with the other materials with $1 \mathrm{wt} . \%$ of pure $\mathrm{M}(1 \% \mathrm{M})$ and $1 \mathrm{wt} . \%$ with the carbon/M composites, e.g. values near $(290 \pm 68)-(331 \pm 23) \mathrm{MPa}$, but showed a more significant increase with the $1 \% \mathrm{M}_{800}$ composite, i.e. $355 \pm 31 \mathrm{MPa}$. Based on this result, a more detailed investigation of the composites containing 1 and $3 \mathrm{wt}$.\% of filler was carried out with the materials obtained at $800{ }^{\circ} \mathrm{C}$, i.e. 1 and $3 \% \mathrm{M}, 1$ and $3 \% \mathrm{M}_{800}$ and 1 and $3 \% \mathrm{M}_{\mathrm{Fe} 800}$ (Figure S1, Supplementary Information). The yield stress of the UHMWPE showed a slight increase with $3 \%$ of the pure M. On the other hand, with 1 and $3 \%$ of the composite $\mathrm{M}_{800}$ the yield stress further increased. It is interesting to observe that the use of the composite 1 and $3 \% \mathrm{M}_{\mathrm{Fe} 800}$ led to a decrease in the yield stress values. It is interesting to observe that the use of the composite 1 and $3 \% \mathrm{M}_{\mathrm{Fe} 800}$ did not lead to an increase so 
expressive in the yield stress values when compared to the samples with the 1 and $3 \% \mathrm{M}_{800}$. This behavior is probably related to differences in the carbon structures deposited on the clay. However, an increase in the yield stress of composite 1 and $3 \% \mathrm{M}_{\mathrm{Fe} 800}$ was observed when compared to the UHMWPE.

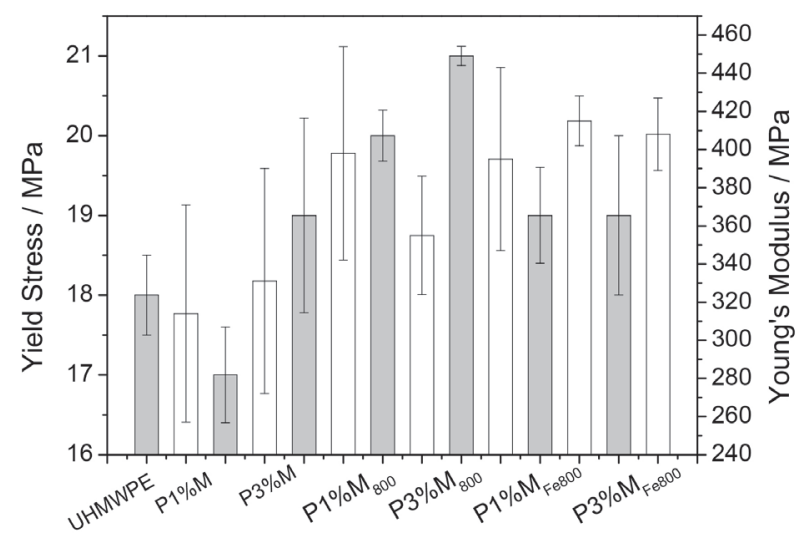

Figure 6. Yield strength and Young's module values obtained from the stress-strain curves of pure UHMWPE, P1\%M, P3\% M, P1\% $\mathrm{M}_{800}$, $\mathrm{P} 3 \% \mathrm{M}_{800}, \mathrm{P} 1 \% \mathrm{M}_{\mathrm{Fe} 800}$ and $\mathrm{P} 3 \% \mathrm{M}_{\mathrm{Fe} 800}$.

The Young's module values increased for all the obtained materials from $314 \pm 57 \mathrm{MPa}$ for pure UHMWPE to $395 \pm 48 \mathrm{MPa}$ for $3 \% \mathrm{M}_{800}$ and $408 \pm 19 \mathrm{MPa}$ for $3 \% \mathrm{M}_{\mathrm{Fe} 800}$. It is interesting to compare the large increase in the Young's module of approximately 26-30\% even with an inefficient processing method based on compression. For example, the improvement of the Young's module or the rigidity of UHMWPE due to addition of montmorillonite has already been reported in literature using methods such as extrusion and torque rheometer. Babiker and $\mathrm{Yu}^{7}$ have described an increase of $14 \%$ of Young's modulus with $1 \mathrm{wt} . \%$ of an organophilic clay by extrusion process. Liu et al. ${ }^{27}$ showed the increase of $42 \%$ of Young's modulus to UHMWPE with $1 \mathrm{wt}$ \% of a pure montmorillonite clay blended in torque rheometer.

The elongation at break of pure UHMWPE $569 \pm 41 \%$ strongly decreased to $467 \pm 20$ and $432 \pm 55 \%$ after the addition of pure MMT at 1 and 3 wt.\%, respectively (Figure S1, Supplementary Information). This result is expected due to the poor interface/interaction of the polymer with the inorganic filler MMT. ${ }^{7}$ On the other hand, the addition of the carbon/clay particles, e.g. $1 \% \mathrm{M}_{800}$, and $3 \% \mathrm{M}_{800}$, caused a significantly smaller decrease, $489 \pm 23$ and $453 \pm 22 \%$, respectively, which suggests a much more effective interaction of the UHMWPE with the carbon/ clay particles.

TG analyses (in $\mathrm{N}_{2}$ atmosphere) for pure UHMWPE and the obtained materials showed a single weight loss near $380{ }^{\circ} \mathrm{C}$ related to the polymer thermal degradation
(Figure S2, Supplementary Information). The $\mathrm{T}_{\text {onset }}$ (degradation start temperature) values obtained from thermogravimetric curve are shown in Figure 7 . It can be observed that the $\mathrm{T}_{\text {onset }}$ of $445^{\circ} \mathrm{C}$ for pure UHMWPE decreased to 380 and $400{ }^{\circ} \mathrm{C}$ with 1 and $3 \% \mathrm{M}$, respectively. On the other hand, a significant increase on the $\mathrm{T}_{\text {onset }}$ is observed for the materials with $1 \% \mathrm{M}_{800}, 3 \% \mathrm{M}_{800}, 1 \% \mathrm{M}_{\mathrm{Fe} 800}$ and $3 \% \mathrm{M}_{\mathrm{Fe} 800}$ of $461,472,453$ and $465{ }^{\circ} \mathrm{C}$, respectively.

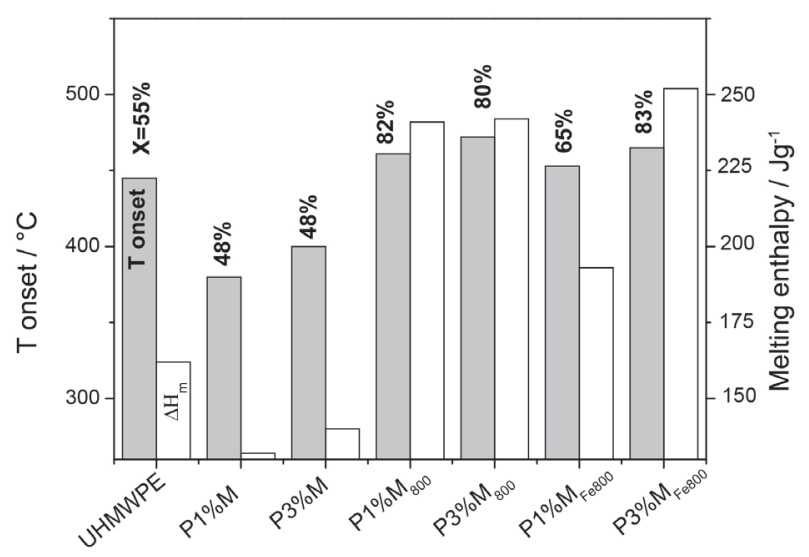

Figure 7. $\mathrm{T}_{\text {onset }}$, melting enthalpy and degree of crystallinity $(\mathrm{X})$ of the pure UHMWPE, P1\%M, P3\%M, P1\% $\mathrm{M}_{800}, \mathrm{P} 3 \% \mathrm{M}_{800}, \mathrm{P} 1 \% \mathrm{M}_{\mathrm{Fe} 800}$ and $\mathrm{P} 3 \% \mathrm{M}_{\mathrm{Fe} 800}$.

Babiker and Muhuo ${ }^{7}$ have reported an increase of the thermal stability of UHMWPE with the addition of MMT. At 5\% MMT (Cloisite ${ }^{\circledR} 15 \mathrm{~A}$ ) content they observed an increase in thermal stability of $6.2 \%$. Ramazani et al. ${ }^{2}$ also observed an increase in thermal stability by introducing hydroxyl-functionalized spherical fumed silica nanoparticles at UHMWPE, with an increase of $4 \%$ at concentrations of $0.5,1.5$ and 2.5 wt. $\%$. The use of the carbon/M composite as filler at $3 \%$ in the current work promoted a $6 \%$ increase in the thermal stability. These results indicate that the presence of the composites $\mathrm{M}_{\mathrm{Fe} 800}$ and $\mathrm{M}_{\mathrm{Fe} 800}$ is likely acting as thermal insulators ${ }^{5}$ or a barrier delaying the polymer degradation.

DSC analyses were also carried out for the pure UHMWPE and modified polymers (Figure S3, Supplementary Information) and the obtained melting enthalpies and the respective crystallinities are also shown in Figure 7. The crystallinity values were obtained using the reference $\Delta \mathrm{H}_{\mathrm{M}}$ (enthalpy of melting) $=293.6 \mathrm{~J} \mathrm{~mol}^{-1}$, which is used for $100 \%$ crystalline UHMWPE. ${ }^{9}$

It can be observed that, although the melting temperature did not change significantly, i.e. $132-136{ }^{\circ} \mathrm{C}$, the presence of the pure clay and the carbon/clay particles strongly affected the UHMWPE properties. For example, the $\Delta \mathrm{H}_{\mathrm{m}}$ of $162 \mathrm{~J} \mathrm{~g}^{-1}$ decreased to 132 and $140 \mathrm{~J} \mathrm{~g}^{-1}$, whereas the crystallinity decreased from 55 to $48 \%$ in the presence of 
1 and $3 \%$ pure clay, respectively. These results suggest that the presence of the pure clay hindered the UHMWPE crystallization during cooling. Similar results have been observed in previous work with UHMWPE. ${ }^{27}$ On the other hand, the presence of the carbon/clay particles significantly increased the $\mathrm{H}_{\mathrm{M}}$ values to $\Delta \mathrm{H}_{\mathrm{M}} 193-252 \mathrm{~J} \mathrm{~g}^{-1}$ and also the crystallinity to $65-83 \%$. These results indicate that the carbon/clay particles are likely playing a role as nucleating agents. This nucleating effect has been discussed before for talc, silica and montmorillonite. ${ }^{28-30}$

Although the reasons for this remarkable increase in crystallinity is not well understood, one can envisage that the carbon nanofiber hydrophobic high surface has a good interaction with the UHMWPE hydrophobic chains. This interaction can lead to an organization of the polymer chains and induce an interaction and a more efficient crystallization. In fact, previous work with carbon nanotubes showed better crystallization of poly(lactic acid) (PLA) and polyethylene (PE) ${ }^{31}$ It is interesting to observe that XRD results suggested very similar crystallinities of UHMWPE $(62 \%)$ with the other materials, i.e. $58,56,55,53,55$ and $57 \%$ for $\mathrm{P} 1 \% \mathrm{M}, \mathrm{P} 3 \% \mathrm{M}, \mathrm{P} 1 \% \mathrm{M}_{800}, \mathrm{P} 3 \% \mathrm{M}_{800}, \mathrm{P} 1 \% \mathrm{M}_{\mathrm{Fe} 800}$ and $\mathrm{P} 1 \% \mathrm{Fe} 800$, respectively, where $\mathrm{P}$ is the polymer. Crystallite sizes estimated by the Scherrer equation showed for all samples similar average sizes of $23-26 \mathrm{~nm}$. These results suggest that the increase in crystallization indicated by the $\Delta \mathrm{H}_{\mathrm{M}}$ values are not related to these larger crystallite sizes. Probably, the increase in the melting enthalpies is related to the small crystalline zones (invisible to XRD) near to the interface carbon nanofibers-polymer chain as represented schematically in Figure 8. Although more detailed studies are necessary to further investigate this point, the presence of this interface can justify the mechanical properties results as increase of the Young's modulus and yield strength, and decrease of the elongation at break.

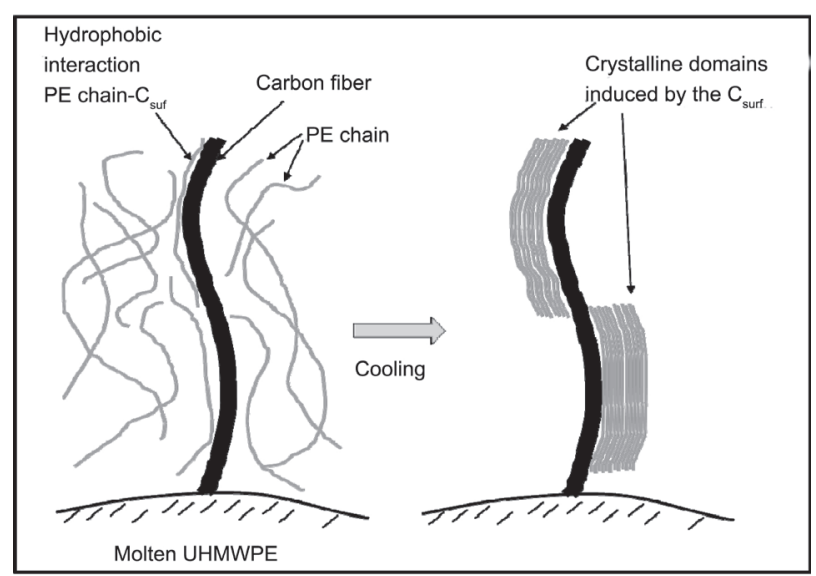

Figure 8. Schematic representation of the effect of carbon nanostructures on the crystallization of UHMWPE.

The SEM images shown in Figure 9 are related to the fractures regions after tensile test. Pure UHMWPE, apparently showed the polymer chains aligned with the flow. Similar result has been observed before. ${ }^{7}$ On the other hand, the addition of clay particles (1 and $3 \mathrm{wt} . \%$ ) led to the formation of defects and voids (highlighted by circles) related to tearing of the film near to the defective regions which are visible in the images (as shown by the arrow).

The composites of the UHMWPE with the carbon/clay, e.g. $\mathrm{P} 1 \% \mathrm{M}_{800}$ and $\mathrm{P} 3 \% \mathrm{M}_{800}$ only slight surface tear were observed, which did not lead to the formation of voids and

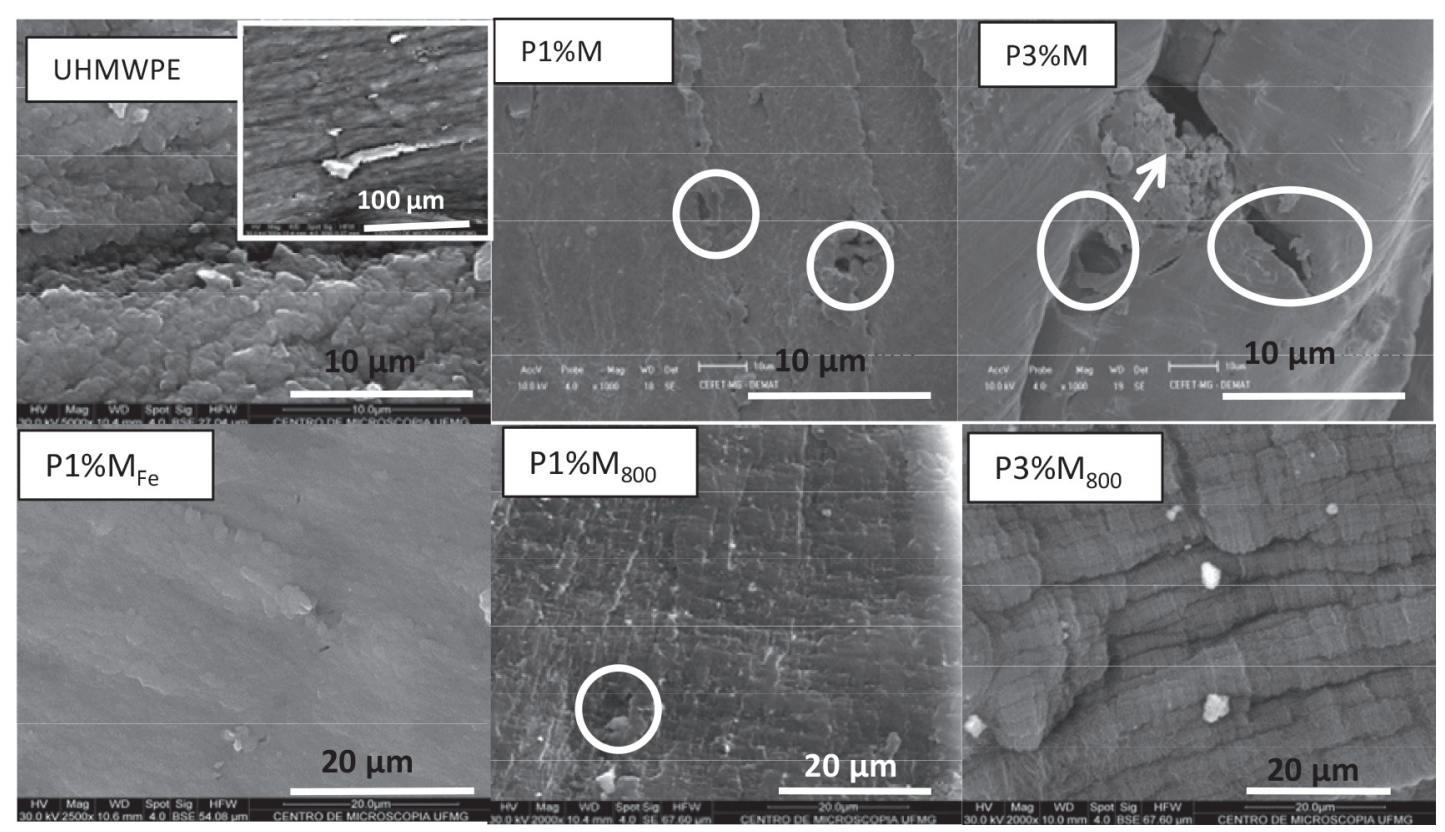

Figure 9. SEM images of pure polymer (UHMWPE) and the materials $\mathrm{P} 1 \% \mathrm{M}, \mathrm{P} 3 \% \mathrm{M}, \mathrm{P} 1 \% \mathrm{M}_{800}, \mathrm{P} 3 \% \mathrm{M}_{800}$ and $\mathrm{P} 1 \% \mathrm{M}_{\mathrm{Fe} 800}$. 
defects. Probably, this result is related to the interaction of the polymer chain and carbon particles preserving the polymer structure.

\section{Conclusions}

Montmorillonite, a typical filler used in polymers, can be modified by the synthesis of carbon nanofibers on the clay surface. These hydrophobic surface nanostructures should have a more efficient interaction with the hydrophobic UHMWPE chains leading to a much higher dispersion of the filler particles throughout the polymeric matrix. These fillers have significantly improved the mechanical properties of the UHMWPE and especially the thermal behavior with an important increase on the decomposition temperature and crystallinity. This is especially relevant for UHMWPE which demands relatively high processing temperatures.

\section{Supplementary Information}

Supplementary data are available free of charge at http://jbcs.sbq.org.br as PDF file.

\section{Acknowledgments}

The authors thank to CNPq, INCT Midas, FAPEMIG (Universal 2014) and CAPES.

\section{References}

1. Kelly, J. M.; J. Macromol. Sci. 2002, 42, 355.

2. Ramazani, S. A. A.; Saremi, M. G.; Amoli, B. N.; Izadi, H.; Polym. Compos. 2012, 33, 1858.

3. Peng Chang, B.; Md Akil, H.; Bt Nasir, R.; Khan, A.; Tribol. Int. 2015, 88, 252.

4. Wen, J. P.; Yin, P.; Zhen, M. H.; Mater. Lett. 2008, 62, 4161.

5. Babaei, A.; Ghaffarian, S. R.; Khorasani, M. M.; Abdolrasouli, M. H.; J. Macromol. Sci., Part B: Phys. 2014, 53, 829.

6. Gai, J. G.; Li, H. L.; J. Appl. Polym. Sci. 2007, 106, 3023.

7. Babiker, M. E.; Muhuo, Y.; Polym. Polym. Compos. 2011, 19 , 685.

8. Santhoskumar, A. U.; Lakshmi, S. U.; Palanivelu, K.; Kartik, R.; 2013 International Conference on Advanced Nanomaterials and Emerging Engineering Technologies; IEEE: Chennai, India, 2013, 107-111.

9. Xu, T.; Farris, R. J.; Polym. Eng. Sci. 2007, 47, 1544.

10. Puertolas, J. A.; Kurtz, S. M.; J. Mech. Behav. Biomed. Mater. 2014, 39, 129.

11. Chukov, D. I.; Stepashkin, A. A.; Maksimkin, A. V.; Tcherdyntsev, V. V.; Kaloshkin, S. D.; Kuskov, K. V.; Bugakov, V. I.; Composites, Part B 2015, 76, 79.
12. Costa, D. A. S.; Mambrini, R. V.; Fernandez-Outon, L. E.; Macedo, W. A. A.; Moura, F. C. C.; Chem. Eng. J. 2013, 229, 35.

13. de Mesquita, J. P.; Reis, L. S.; Purceno, A. D.; Donnici, C. L.; Lago, R. M.; Pereira, F. V.; J. Chem. Technol. Biotechnol. 2013, 88,1130 .

14. Medeiros, M. D.; Cancado, T. M.; Leite, C. M. M.; Lago, R. M.; J. Chem. Technol. Biotechnol. 2012, 87, 1654.

15. Teixeira, A. P. C.; Purceno, A. D.; Barros, A. S.; Lemos, B. R. S.; Ardisson, J. D.; Macedo, W. A. A.; Nassor, E. C. O.; Amorim, C. C.; Moura, F. C. C.; Hernandez-Terrones, M. G.; Portela, F. M.; Lago, R. M.; Catal. Today 2012, 190, 133.

16. Purceno, A. D.; Teixeira, A. P. C.; de Souza, N. J.; FernandezOuton, L. E.; Ardisson, J. D.; Lago, R. M.; J. Colloid Interface Sci. 2012, 379, 84.

17. Purceno, A. D.; Barrioni, B. R.; Dias, A.; da Costa, G. M.; Lago, R. M.; Moura, F. C. C.; Appl. Clay Sci. 2011, 54, 15.

18. Teixeira, A. P. C.; Santos, E. M.; Vieira, A. F. P.; Lago, R. M.; Chem. Eng. J. 2013, 232, 104.

19. Lemos, B. R. S.; Soares, E. A. R.; Teixeira, A. P. C.; Ardisson, J. D.; Fernandez-Outon, L. E.; Amorim, C. C.; Lago, R. M.; Moura, F. C. C.; Chemosphere 2016, 159, 602.

20. Teixeira, I. F.; Medeiros, T. P. V.; Freitas, P. E.; Rosmaninho, M. G.; Ardisson, J. D.; Lago, R. M.; Fuel 2014, 124, 7.

21. Teixeira, A. P. C.; Tristao, J. C.; Araujo, M. H.; Oliveira, L. C. A.; Moura, F. C. C.; Ardisson, J. D.; Amorim, C. C.; Lago, R. M.; J. Braz. Chem. Soc. 2012, 23, 1579.

22. Oliveira, A. A. S.; Tristao, J. C.; Ardisson, J. D.; Dias, A.; Lago, R. M.; Appl. Catal., B 2011, 105, 163.

23. Oliveira, A. A. S.; Teixeira, I. F.; Ribeiro, L. P.; Tristao, J. C.; Dias, A.; Lago, R. M.; J. Braz. Chem. Soc. 2010, 21, 2184.

24. Jalil, M. E. R.; Vieira, R. S.; Azevedo, D.; Baschini, M.; Sapag, K.; Appl. Clay Sci. 2013, 71, 55.

25. ASTM D 638, Standard Test Method for Tensile Properties of Plastics; American Society for Testing and Materials, New York, 2008.

26. Lucchese, M. M.; Stavale, F.; Ferreira, E. H. M.; Vilani, C.; Moutinho, M. V. O.; Capaz, R. B.; Achete, C. A.; Jorio, A.; Carbon 2010, 48, 1592.

27. Oliveira, L. C. A.; Lago, R. M.; Fabris, J. D.; Solar, C.; Sapag, K.; Braz. J. Chem. Eng. 2003, 20, 45.

28. Liu, C.; Qiu, H. T.; Liu, C. J.; Zhang, J.; Polym. Compos. 2012, 33, 1987.

29. Shakoor, A.; Thomas, N. L.; Polym. Eng. Sci. 2014, 54, 64.

30. Chang, B. P.; Akil, H. M.; Nasir, R. B.; Khan, A.; Tribol. Int. 2015, 88, 252.

31. Riviere, P.; Nypelo, T.; Rojas, O. J.; Klug, A.; Mundigler, N.; Wimmer, R.; J. Therm. Anal. Calorim. 2017, 127, 2059.

Submitted: January 12, 2017

Published online: July 14, 2017 